\title{
Fen Öğretiminde Kullanılan Hologram Uygulamalarına Yönelik Fen Bilimleri Öğretmenlerinin Görüşleri
}

\author{
Science Teachers' Opinions about the Use of Hologram Applications in Science \\ Education
}

\author{
Doç. Dr. Hasan BAKIRCI ${ }^{1}$, Öğretmen Nurten GÖK ${ }^{(D 2}$, Doç. Dr. Hüseyin ARTUN ${ }^{(D}{ }^{3}$
}

\begin{abstract}
$\ddot{O} z$
Covid-19 salgını, uzaktan eğitimi zorunlu hale getirmiştir. Bu eğitim yaklaşımında; bilgisayar, tablet, akıllı telefon ve televizyon gibi teknolojik ürünler oldukça fazla kullanılmaktadır. Bu teknolojilerin yanında son dönemlerde öğrenme ortamlarında; simülasyonlar, animasyonlar, hologram, artırılmıs ve sanal gerçeklik gibi öğretim teknolojilerinin kullanıldığ hologram teknolojisi ile ilgili yapılan sınırlı sayıdaki çalışmanın sonuçlarına göre öğrenme ortamlarında olumlu katkılarının olduğu söylenebilir. Bundan dolayı hologram teknolojisinin öğrenme ortamlarında kullanımına yönelik öğretmen görüşlerini belirleyen bu çalışmanın alanyazına katkı sağlayacağ düşünülmektedir. Bu kapsamda araştırmanın amacı, Fen Bilimleri öğretmenlerinin fen öğretiminde hologram teknolojisi uygulamalarına yönelik görüşlerini belirlemektir. Araştırmanın yöntemi, nitel araştırma yaklaşımlarından olgubilim deseni olarak belirlenmiştir. Araştırmanın çalışma grubunu ise, 2020-2021 eğitim öğretim y1lında Doğu Anadolu Bölgesi'nde görev yapmakta olan 10 (4 erkek, 6 kadın) Fen Bilimleri öğretmeni oluşturmaktadır. Veriler, araştırmacılar tarafından geliştirilen yarı yapılandırılmış görüşme formu ile toplanmıştır. Elde edilen veriler, içerik analiz yöntemi ile çözümlenmiştir. Çalışmanın sonucunda Fen Bilimleri öğretmenleri, hologram teknolojisinin fen öğretiminde kullanılmasının birçok yararlarının olduğunu ifade etmişlerdir. Bu yararlar; öğrencilerin konuya dikkatlerini çektiği, kavramların öğrenilmesini kolaylaştırdığı, akademik başarıyı artırdığı, konuları somutlaştırdığı ve pekiştirdiği şeklindedir. Çalışmaya katılan öğretmenlerin bazıları hologram teknolojisini fen öğretiminde yeterli düzeyde kullanamadıklarını belirtmişlerdir. Dijital hologram teknolojisinin sınıf ortamına taşınabilmesi için, öğretmenlerin bu teknolojiden haberdar olması ve bu konu hakkında çalışmalara katılmaları gerektiği düşünülmektedir.
\end{abstract}

Anahtar Kelimeler: Fen öğretimi, fen bilimleri öğretmenleri, hologram teknolojisi

Makale Türü: Araştırma

\begin{abstract}
Distance learning became mandatory with Covid-19 outbreak. The use of technological products such as computers, tablets, smartphones and televisions have increased. In addition, teaching technologies such as simulations, animations, hologram, augmented and virtual reality are used in the learning environment. Among these technologies, limited number of studies on hologram technology shows that it has positive contributions to the learning environment. Therefore, it is thought that determining the teachers' perspective on hologram technology in the learning environment will contribute to the literature. The research aims to determine the opinions of science teachers about hologram technology applications in science teaching. Phenomenology design, which is one of the qualitative research approaches, was used in the study. This research consists of 10 (4 male, 6 female) science teachers working in the Eastern Anatolia Region in the 2020-2021 academic year. The data were collected using a semi-structured interview form which is developed by the researchers. The data were analysed content analysis. Results of the study show that using hologram technology in science teaching has many benefits. These benefits
\end{abstract}

\footnotetext{
${ }^{1}$ Van Yüzüncü Yıl Üniversitesi, Eğitim Fakültesi, hasanbakirci09@gmail.com

${ }^{2}$ Milli Eğitim Bakanlığı, ng_nrtngok_9@hotmail.com

${ }^{3}$ Van Yüzüncü Y1l Üniversitesi, Eğitim Fakültesi, huseyinartun@gmail.com
}

Atıf için (to cite): Bakırcı, H., Gök, N., \& Artun, H. (2021). Fen öğretiminde kullanılan hologram uygulamalarına yönelik fen bilimleri öğretmenlerinin görüşleri. Afyon Kocatepe Üniversitesi Sosyal Bilimler Dergisi, 23(4), 1334-1348. 
increase students' attention, facilitating the learning process of concepts, increasing academic success, concretising and reinforcing subjects. Some of the teachers who participated in the study stated that they did not use hologram technology in science teaching at a sufficient level. To bring digital hologram technology to the classroom environment, teachers should be aware of these technologies and participate in studies on this subject.

Keywords: Science teaching, science teachers, hologram technology

Paper Type: Research

Giriş

İnsan yaşamında önemli rolü olan en temel ögeler, eğitim ve teknoloji olup bu iki kavram iç içedir ve sürekli beraber ilerlemektedir. Her iki öge de insanın doğal ve sosyal çevresine egemen olması için gerekli olan iki temel araç olmuştur. Diğer bir deyişle eğitim ve teknoloji; insanoğlunun mükemmelleşmesi, kültürlenmesi ve geliştirilmesi, doğaya ve çevresine karşı etken ve nüfuzlu bir unsur haline gelmesinde rol almıştır (Bozkuş, 2002). Bilimsel ve teknolojik toplum yaşamı için bireyin gerekli yeteneği ve bilgiyi kazanması, teknoloji-eğitim ilişkisinin kültürel yönü ile ilgilidir. Diğer taraftan, bir teknolojinin gereksinim duyduğu nitelikteki insan gücünü yetiştirme ekonomik yönünü ifade ederken; teknolojinin eğitime uygulanması ya da teknolojik olanaklardan eğitim alanında yararlanma biçimi ise eğitsel yönünü ifade etmektedir (Alkan, 2005). Eğitim alanında teknolojinin kullanılmasında asıl amaç; etkili, verimli, kalıcı öğrenme sağlamak ve öğrencinin aktif olarak öğretime katılması sonucu, öğrenilen bilgilerin hatırda kalma seviyesini artırmaktır (Khurmyet, 2016).

Teknolojinin kullanımı, birçok alanda olduğu gibi öğrenme ortamlarında da etkisini göstermiştir. Öğrenme ortamlarında teknolojiden en iyi şekilde yararlanmak için araştırmacılar farklı çalışmalar yapmışlardır. Bu çalışmalar sonucunda, "Eğitim Teknolojisi”" adında bir bilim dalı ortaya çıkmıştır. Bu bilim dalının odaklandığı konular kapsamında yapılacak olan araştırma ve incelemeler sonucunda elde edilen kuramsal bilgilerin, öğrenme ortamlarında karşılaşılabilecek teknolojik sorunlarına somut çözümler üretmektedir (Sotiriou ve Bogner, 2008; Tüfekçi-Hotomaroğlu, 1997). Öğrenme ortamlarında teknolojiye olan ihtiyacın gün geçtikçe artığ1 söylenebilir. Özellikle salgın nedeniyle uzaktan eğitime geçilmesi, öğrenme ortamlarında teknoloji kullanımının önemini artırmıştır. Tablet, bilgisayar ve akıllı telefon uzaktan eğitimde en çok kullanılan teknoloji ürünleri olmuştur. Bu teknolojik ürünler yanında zoom, google drive ve google meet gibi bilgisayar programları kullanılmıştır. Bu teknoloji ve programların öğrenme ortamında kullanılması uzaktan eğitim ile günümüzde yaygınlaştığı söylenebilir. Bu teknolojiler ve programlar, öğrencilerin birçok duyu organına hitap ettiği ve bireysel farklıları dikkate aldığı için öğrenme ortamlarında karşılaşılan birçok sorunu ortadan kaldıracağı düşünülmektedir (Orcos ve Magrenan, 2018). Dolayısıyla uzaktan eğitim aracıllğıyla öğrenme ortamında yaygın olarak kullanılmaya başlayan bu teknolojiler örneğinde olduğu gibi hologram teknolojisinin öğrencilerin derse aktif katılımını sağlayabileceği, konuyu daha iyi anlamalarına yardımcı olabileceği düşünülmektedir. Bundan dolayı öğrenme ortamlarında hologram teknolojisi uygulamalarına ilişkin Fen Bilimleri öğretmenlerinin görüşlerinin belirlemesinin önemli olduğu söylenebilir.

21. yüzyılda eğitim ve teknoloji bir bütün olarak düşünülmekte, eğitim ve öğretim programları ele alındığında; teknoloji entegrasyonuna uygun derslerden birinin de Fen Bilimleri dersi olduğu düşünülmektedir. 2018 yılında yenilenen Fen Bilimleri Dersi Öğretim Programı, fen eğitiminin amaçlarını geniş bir şekilde ele alan ve teknoloji çağında olmamız sebebiyle fen eğitimine teknolojinin de entegre edilebileceğini gösteren yenilikleriyle dikkat çekmiştir. $\mathrm{Bu}$ anlamda öğretim programına eklenen Temel Yeterlilikler Çerçevesi, 21. yüzyıl öğrencilerinin bilim ve teknoloji alanında sahip olması gereken yeterlilikleri ele almaktadır (Türk, 2020). Bu yeterliliklerden biri de dijital yetkinlik olmuştur. Bu yetkinlik, öğrencilerin bilgi iletişim teknoloji aracılığıyla bilgiye ulaşması, bilginin saklanması, üretilmesi, sunulması ve 
değerlendirmesi olarak tanımlanmaktadır. $\mathrm{Bu}$ yetkinliğin öğrencilere kazandırılması, öğretmenlerin derslerde öğretim teknolojilerine yer vermesiyle sağlanabileceği düşünülmektedir.

Öğretim teknolojilerinin fen öğretiminde kullanılmasının amacı, öğrencilerin konuya ilişkin dikkatlerini çekerek etkili öğrenmelerini sağlamaktır (Durukan, Artun ve Temur, 2020). Fen Bilimleri dersinde öğretmenler, hücre konusunu mikroskop yardımıyla işlemektedir. Öğretmenler, Fen Bilimleri dersinde mikroskop kullanımının yanında bilgisayar animasyonlarını, simülasyonları, multimedyaları ve sanal laboratuvarları kullanmaktadır (Kara, 2018; Sipahioğlu, 2019). Her geçen y1l teknolojinin gelişmesiyle birlikte bu teknolojilerin yanında farklı teknolojilerin de öğrenme ortamlarında kullanıldığg görülmektedir. Fen eğitimine ilişkin öğrenme ortamlarında hücrenin öğretilmesi konusunda Artırılmış Gerçeklik ve Sanal Gerçeklik teknolojilerinin kullanıldığı tespit edilmiştir (Artun, Durukan ve Temur, 2020; Walker, 2013). Bu teknolojiler sayesinde hücre konusu üç boyutlu olarak gösterilerek, öğrencilerin hücre konusunu etkili öğrenmesi sağlanmaktadır (Kara ve Bakırcı, 2018; Türk, 2020). Salgın nedeniyle tüm öğretim kademelerinde uzaktan eğitimin önem kazanmasıyla birlikte üç boyutlu bu teknolojilerin öğrenme ortamında kullanımının önemi daha artmıştır. Bu öğretim teknolojilerden birisinin de hologram teknolojisi olduğu söylenebilir.

Üç boyut teknolojisi olan hologram; lazer ışı̆̆ı gibi tutarlı bir 1şıktan gelen 1şık 1şınları tarafından oluşturulan ve holografik projeksiyonla oluşturulmuş üç boyutlu görüntünün oluşmasını sağlayan bir görselleştirme aracıdır (Katsioloudis ve Jones, 2018). Son zamanlarda adından en çok söz ettiren yenilikçi teknolojilerden birisi de öğrenme ortamlarında kullanılan hologram teknolojisidir. Hologram teknolojisinin öğrenme ortamlarda tercih edilmesinin nedeni, kişiye özel öğrenme sağlama, birden çok duyu organına hitap etme, ulaşabilir ve ekonomik olma gibi özelliklerin etkili olduğu söylenebilir (Aslan, 2017; Katsioloudis ve Jones, 2018). Hologramın bu özellikleri, gelecekte öğrenme ortamlarının vazgeçilmez teknolojisi olacağına bir işarettir. Bu teknolojinin fen öğretiminde kullanılması, öğrencilerin teknoloji açısından donanımlı olmalarına katkı sağlamasının yanında fen bilimlerindeki soyut kavramların öğrenilmesini kolaylaştıracağı düşünülmektedir (Huang, Chen ve Chou, 2016; Türk, 2020). Bu konuda yapılan başka bir çalışmada da, hologram teknolojisinin öğrencilerin hızlı öğrenmelerine katkı sağladığı ve kalıcı öğrenmeyi desteklediği saptanmıştır (Aslan ve Erdoğan, 2017). Benzer şekilde hologram teknolojisinin, astronomi konularında öğretmen adaylarının bilgilerini artırdığı görülmüştür (Okulu ve Ünver, 2016). Hologram teknolojisi konusunda yapılan çalışmaların öğrenme ortamlarında olumlu sonuçlarının görülmesi, araştırmacıları bu teknolojiye yönelik çalışmalar yapmaya yöneltmiştir.

Hologram teknolojilerine yönelik alanyazın incelendiğinde, bu teknolojinin öğrenme ortamında birçok olumlu sonuçlarının olduğu görülmüştür. Hologram teknolojisine yönelik uygulamaların kolay ve eğlenceli olabileceği, öğrencilerin motivasyonunu artırabileceği vurgulanmaktadır (Baker, Bakar ve Zulkifli, 2017). Başka bir çalışmada hologram teknolojisinin yüz yüze eğitim için ideal bir öğrenme ortamı sağlamada ve kavram yanılgılarını gidermede etkili olduğu saptanmıştır (Chen ve Wang, 2015). Hologram teknoloji, hücre bölünmesi konusunda öğrencilerin anlamlı öğrenmelerine katkı sağladığı, öğrencilerin hologram teknolojisine konusunda olumlu düşünceye sahip oldukları ve hologram teknolojisinin öğrencilerin motivasyonlarını artırdığı tespit edilmiştir (Orcos ve Magrenan, 2018). Bu konuda yapılan başka bir çalışmada, hologram teknolojisinin dördüncü sınıf öğrencilerinin görselleştirme becerilerine katkı sağladığ 1 , bu teknolojinin öğrenciler üzerinde olumlu etkisinin olduğu ve öğrenme ortamlarında öğretim materyali olarak kullanılabileceği belirlenmiştir (Roslan ve Ahmad, 2017). Öğrenme ortamında kullanılan hologram teknolojisine öğrencilerin olumlu baktıkları ve bu teknolojinin öğrenme ortamında kullanımının öğrencilerin öğrenmelerine kak1 sağladığı görülmüştür (Hackett ve Proctor, 2016). Hologramların öğrencilerin konuları somutlaştırarak öğrenilmesinde etkili olmaktadır (Yamaguchi ve Yoshikawa, 2012). 
Yurt dışında hologram teknoloji ile ilgili yapılan bazı çalışmaların sonuçları verildikten sonra yurt içinde yapılan çalışmalara değinmek gerekir. Hologram teknolojilerinin zamandan tasarruf sağlaması ve ekonomik olması nedeniyle gelecekte öğrenme ortamlarında daha fazla yer alabileceği ortaya koyulmuştur (Şahin ve Uyar, 2019). Etkileşimli hologram destekli materyalin farklı duygu organlarına hitap ettiği, çocukların derse aktif katılımını sağladı̆̆ güdeleyici ve merak uyandırıcı olduğu, kalıcı öğrenmeye katkı sağladığı sonucuna varılmıştır (Turan-Güntepe, 2020). Yapılan başka bir çalışmada ortaokul öğrencilerinin hologram teknolojisi konusunda olumlu tutuma sahip oldukları tespit edilmiştir (Türk, 2020). Ayrıca öğrencilerin derinlik algısını, mekânsal düşünme yeteneğini, zihinsel süreçlerini ve problem çözme becerilerini geliştirmektedir (Okulu ve Ünver, 2016).

Hologram teknoloji ile ilgili yurt dışında birçok çalışmaya rastlanırken, yurt içinde bu konuda sınırlı sayıda olduğu söylenebilir. Özellikle alanyazında fen eğitiminde hologram teknolojisinin kullanımına yönelik çalışmaların ülkemizde sınırlı olduğu görülmektedir (Türk, 2020). Hologram teknolojisinin fen konuların anlaşılmasını kolaylaştırdığı ve kavramların öğretilmesinde etkili olması (Mnaathr ve Basha, 2013) ve fen öğretiminde kullanımının etkili olduğu tespit edilmiştir (Olson, 2013). Hologram teknolojisinin yakın bir zamanda sınıflardan yer alacak olması öngörülmektedir (Ghuloum, 2010). Hologram teknolojinin öğrenme ortamlarında yukarıda bahsedilen faydalarının olması ve ülkemizde bu konuda sinırlı sayıda çalışmanın olması bu çalışmayı önemli kılmaktadır. Bunun yanı sıra fen öğretiminde kullanılan hologram uygulamasına yönelik çok fazla çalışma bulunmamaktadır. Fen Bilimleri dersinde hologram teknolojilerinin kullanımını aktif hale getirilmesi ve öğrencilerin fen konularını etkili öğrenilebilmeleri açısından önemli olduğu düşünülmektedir. Bu araştırmada, Fen Bilimleri dersinin öğretiminde hologram teknoloji uygulamalarının öğrencilerle buluşturulması ve öğrencilerin yenilikçi teknolojilerden haberdar edilmesi bu çalışmayı önemli kılan diğer bir unsur olduğu düşünülmektedir. Ayrıca yenilikçi teknolojilerin fen öğretimine entegre edilebilmesi ve gelişen teknolojiyle ortaya çıkan hologram teknolojisinin hangi boyutta nerelerde kullanıldığının ortaya çıkarılmasının alanyazına katkı sağlayacağına inanılmaktadır. Hologram teknolojisinin kullanım alanlarının hangi yönde olması, bu doğrultuda eğitim programlarında nasıl ve hangi koşullarda yer alması gerektiği konusunda fikir vermesi bakımından bu çalışma önem arz etmektedir. Dolayısıyla bu çalışmanın amacı, Fen Bilimleri öğretmenlerinin fen öğretiminde kullanılan hologram uygulamalarına yönelik görüşlerini belirlemektir. Çalı̧̧manın temel problemi, "Fen Bilimleri öğretmenlerinin Fen Bilimleri derslerinde hologram teknolojileri ile ilgili deneyimleri nelerdir?" şeklindedir. Bu temel araştırma problemi doğrultusunda aşağıdaki sorulara cevap aranmıştır.

1. Fen Bilimleri öğretmenlerinin teknoloji destekli fen öğretimi hakkındaki görüşleri nelerdir?

2. Fen Bilimleri öğretmenlerinin fen öğretiminde hologram teknolojilerinin kullanılması ile ilgili deneyimleri nelerdir?

\section{Yöntem}

\subsection{Araştırmanın Modeli}

$\mathrm{Bu}$ çalışmada, fen öğretiminde kullanılan hologram teknolojisi hakkında Fen Bilimleri öğretmenlerinin görüşlerinin ortaya çıkarılması için nitel araştırma yöntemlerinden olgubilim (fenomenoloji) deseni kullanılmıştır. Olgubilim araştırma deseni, farkında olduğumuz ancak derinlemesine bilgi sahibi olmadığımız olgular üzerine yoğunlaşmaktadır. Yaşadığımız çevrede, kavram, olay, deneyim gibi olgulara sıkça rastlanmaktadır. Fakat bu olgularla tanışık olmak onları tam olarak anladığımızı göstermez. Tamamen yabancı olmayan aynı zamanda da tam anlamını bilmediğimiz olguları araştırmayı amaçlayan çalışmalar için olgubilim deseni uygun bir araştırma yöntemidir (Yıldırım ve Şimşek, 2011). Bu araştırma deseni çalışmanın problemi için uygun veri toplama aracını sağladığı, katılımcı sayısının sınırlı olma imkânı verdiği ve 
derinlemesine veri elde edilmesini sağladığı için bu çalışmada olgubilim desen kullanılmıştır. Fen Bilimleri öğretmenlerinin fen öğretiminde kullandıkları hologram teknolojisinin detaylı bir şekilde araştırılmış olması bu çalışmada olgubilim araştırma deseninin tercih edilmesinde etkili olan diğer bir unsur olduğu söylenebilir.

\subsection{Katılımcilar}

Olgubilime göre tasarlanan çalışmalar, olguyu (fenomeni) tüm yönleriyle deneyim etmiş sınırlı sayıda katılımcı/lar ile yürütülmektedir. Bundan dolayı bu çalışmada katılımcı sayısı sınırlı tutulmuştur. Dolayısıyla bu çalışmanın katılımcılarını, 2020-2021 eğitim öğretim yılında Doğu Anadolu Bölgesi'nde görev yapan 10 Fen Bilimleri öğretmeni (4 erkek, 6 kadın) oluşturmaktadır. Çalışmaya katılan Fen Bilimleri öğretmenleri, amaçlı örnekleme yönteminden ölçüt örnekleme tekniği ile belirlenmiştir. Bir çalışmada araştırılacak olan bir durum belli niteliklere sahip nesneler, olaylar ve kişiler olabilir. Bu durumda, örneklem için belirlenen özellikleri karşılayan durum (olay, nesne ve kişiler vb.) çalışma grubuna alınmaktadır (Büyüköztürk, Kılıç Çakmak, Akgün, Karadeniz ve Demirel, 2008). Bundan dolayı Fen Bilimleri dersinde hologram teknolojisini kullanan öğretmenler çalışmaya dâhil edilmiştir. Bu sayede çalışmaya konu olan hologram teknolojisi konusunda Fen Bilimleri öğretmenlerinin deneyimleri ortaya çıkarılması amaçlanmıştır. Covid-19 salgını sebebiyle katılımcılar ile yüz yüze iletişime geçilememiş̧ir. $\mathrm{Bu}$ yüzden görüşmeler, Zoom programı üzerinde gerçekleştirilmiştir. Çalışmaya katılan Fen Bilimleri öğretmenleri; Ö1, Ö2, Ö3.....Ö10 şeklinde kodlanmıştır. Araştırmaya katılan Fen Bilimleri öğretmenlerinin demografik özelliklerine ilişkin veriler Tablo 1'de verilmiştir.

Tablo 1. Araştırmaya katılan öğretmenlerin demografik özellikleri

\begin{tabular}{ccccc}
\hline Öğretmen & Cinsiyet & Yaş Aralı̆̆ & Öğrenim Düzeyi & Mesleki Deneyim \\
\hline Ö1 & Kadın & $23-26$ & Yüksek lisans & 3 \\
\hline Ö2 & Kadın & $27-30$ & Lisans & 5 \\
\hline Ö3 & Erkek & $27-30$ & Lisans & 4 \\
\hline Ö4 & Erkek & $31-34$ & Yüksek lisans & 12 \\
\hline Ö5 & Kadın & $23-26$ & Lisans & 2 \\
\hline Ö6 & Kadın & $23-26$ & Lisans & 3 \\
\hline Ö7 & Kadın & $27-30$ & Lisans & 4 \\
\hline Ö8 & Erkek & $27-30$ & Yüksek lisans & 5 \\
\hline Ö9 & Erkek & $27-30$ & Yüksek lisans & 3 \\
\hline Ö10 & Kadın & $23-26$ & Lisans & 2 \\
\hline
\end{tabular}

\subsection{Veri Toplama Aracı}

$\mathrm{Bu}$ çalışma, olgubilim desenine göre planlanmıştır. Bundan dolayı çalışmada veri toplama aracı olarak yarı yapılandırılmış görüşme formu kullanılmıştır. Birçok olgubilim desenli çalışmalarda veriler genellikle yarı yapılandırılmış görüşme formu ile toplanmaktadır (Karademir, Sarıkahya ve Altunsoy, 2017).Yarı yapılandırılmış görüşme formunda, araştırmacı soruları önceden hazırlar ve görüşme sırasında katılımcılara kısmen esneklik sunarak oluşturulan soruların yeniden düzenlenmesini ve tartışılmasını sağlar (Ekiz, 2009; Patton, 2002). Araştırmanın amacına yönelik olarak hazırlanan görüşme formunda teknoloji destekli fen öğretimi programı, fen eğitiminde kullanılabilecek teknolojilerin avantajları ve sınırlılıkları, öğretim teknolojisi, hologram teknolojisi, hologram teknolojisinin öğrenme ortamlarında kullanılabilirliğine yönelik görüşme soruları yer almaktadır.

Görüşme formunda yer alan sorular; çalışmanın amaçları doğrultusunda cevaplanması kolay açık ve anlaşılır, katılımcıyı utanmasına veya sıkılmasına sebep olmayacak türden oluşturulmuştur. Görüşme formundaki soruların konuyu tam olarak içerip içermediğini ve amacına hizmet edip etmemesi ortaya çıkarmak için uzman görüşüne başvurulmuştur. $\mathrm{Bu}$ uzmanların ikisi fen alanında öğretim üyesi, diğer ikisi de Fen Bilimleri öğretmenidir. Bu 
öğretim üyesinden biri Fen Bilgisi Eğitimi Bilim Dalında Nitel Veri Analiz dersini yürütmektedir. Diğer öğretim üyesinin ise nitel desenli birçok çalışması bulunmaktadır. Görüşüne başvurulan Fen Bilimleri öğretmenleri, fen eğitiminde yüksek lisans derecesine sahiptir. Görüşme formunda yer alan soruların ön uygulaması üç Fen Bilimleri öğretmeni ile gerçekleştirilmiştir. Ön uygulamadan sonra üç soru yarı yapılandırılmış görüşme formundan çıkarılmıştır. Bu soruların çıkarılma sebepleri; çalışmanın amacına hizmet etmemesi ve soru içeriklerinin benzer olmasından kaynaklanmaktadır. Yarı yapılandırılmış görüşme formunda yer alan soruların son hali aşağıda verilmiştir.

- Teknoloji destekli fen öğretimi hakkında neler söyleyebilirsiniz?

- Fen öğretiminde kullanılan teknolojilere örnekler verebilir misiniz?

- Fen öğretiminde kullanılan teknolojilerin sınırlılıkları neler olduğunu düşünüyorsunuz?

- Hologram teknolojisi hakkında neler söylemek isterseniz?

- Hologram teknolojisinin fen öğrenme ortamlarında kullanılabilirliği ile ilgili görüşleriniz nelerdir?

- Fen Bilimleri dersinde hologram teknolojisinin kullanılması ile ilgili görüşleriniz nelerdir?

\subsection{Geçerlilik ve Güvenirlik}

Geçerlik ve güvenirlik kavramları araştırmalarda en yaygın olarak kullanılan iki kriterdir Güvenirlik, araştırma sonuçlarının başka durumları yansıtabildiği ya da başka durumlara uygulanabildiği olgusu üzerinde durmaktadır (Ekiz, 2009). Nitel araştırmalarda geçerlik ise, araştırmacının araştırdığı konuyu olduğu şekliyle ve olabildiğince tarafsız olarak gerçekleşmesi anlamına gelmektedir (Yıldırım ve Şimşek, 2011). Bu araştırmada geçerliliği sağlamak için, her duruma ait bilgiler ortaya konmuş, katılımcıların kendi görüşlerini ortaya koymaları için imkânlar oluşturulmuştur. Çalışmanın dış geçerliliğini (aktarılabilirliğini) sağlamak için, çalışmanın her aşaması ayrıntılı olarak açıklanmıştır. Bunun yanı sıra çalışmanın amacı doğrultusunda amaçlı örneklem kapsamında katılımcılar seçilmiştir. Çalışmanın tutarlılığını sağlamak için veriler, üç farklı araştırmacı tarafından kod, tema ve kategoriler şekline getirilerek okuyucuların anlamaları kolaylaştırılmıştır. Çalışmanın teyit edilebilirliğini sağlamak için, mülakat ile elde edilen veriler katılımcıların görüş̧lerine sunulmuştur. Mülakat verilerine eklemek ya da çıkarmak istedikleri verinin olup olmadıkları ortaya çıkarmak adına katılımcı teyidi yapılmıştır.

\subsection{Verilerin Analizi}

Araştırmada verilerin analizi, katılımcıların görüşlerini derinlemesine ve doğrudan ifade edebilmesi, katılımcılardan elde edilen verilerin derinleştirilerek incelenebilmesi için içerik analiz yöntemi kullanılmıştır. İçerik analizinde verilerin derinlemesine işlenmesi, tüm ayrıntıları ile detaylandırılması ve kavram ile temaların ortaya çıkarılması mümkün olmaktadır (Çepni, 2014). Veriler ses kayıtları ile alınmış ardından yazı formatına dönüştürülmüştür. Araştırma problemi kapsamında olmayan kısımlar çıkarılmıştır. Hata olasılığını en aza indirmek için her katılımcıya ait yazılı görüşler katılımcıya sunulmuş ve katılımcının onayı alınmıştır. Ardından araştırma verileri birbirinden bağımsız iki farklı araştırmacı ve bir uzman tarafından analiz edilmiştir. Bu iki araştırmacı, yüksek lisans derecesine sahip olup Nitel Veri Analiz dersini almıştır. Veri analizinde görev alan uzman ise fen öğretim alanında öğretim üyesidir. Araştırmada deneyimli uzmanların yer alması, araştırmanın güvenirliğini olumlu etkilediği söylenebilir. Araştırmacılar tarafından kod ve temalar çıkarılmıştır. Ardından görüş birliğine varılan ve varılamayan noktaların tespit edilmesi için araştırmacılar bir araya gelmiştir. Analize son şeklinin verilmesinde Miles ve Huberman'ın (1994) geliştirdiği formül kullanılmıştır. Formüle göre (Güvenirlik=Görüş Birliği / Görüş Birliği + Görüş Ayrılığı) tabi tutulan 
analizlerde araştırmacılar arasındaki uyum güvenirliği katsayısı 0.86 olarak bulunmuştur (Miles ve Huberman, 1994).

\subsection{Etik Kurul Kararı}

Sosyal ve Beşeri Bilimleri Yayın Etik Kurulu'nun 17/02/2021 tarih ve 2021/02-14 sayılı kararı gereği; Yürütücülüğünü yapmayı tasarladığınız, "Fen Bilimleri Öğretmenlerinin Fen Öğretiminde Kullanılan Hologram Uygulamalarına Yönelik Görüşleri" adlı çalışmanızın Sosyal ve Beşeri Etik Kuralları ve İlkeleri çerçevesinde herhangi bir sakınca olmadığına karar verilmiştir.

\section{Bulgular}

Araştırmada Fen Bilimleri öğretmenlerinin fen öğretiminde kullanılan hologram uygulamalarına yönelik görüşleri belirlenmeye çalışılmıştır. Teknoloji destekli fen öğretimi hakkında Fen Bilimleri öğretmenlerinin görüşleri Tablo 2'de verilmiştir.

Tablo 2. Teknoloji destekli fen öğretimi hakkında fen bilimleri öğretmenlerinin görüşleri

\begin{tabular}{|c|c|c|c|c|c|c|c|c|c|c|c|c|}
\hline Tema & Kodlar & Ö1 & Ö2 & Ö3 & Ö4 & Ö5 & Ö6 & Ö7 & Ö8 & Ö9 & Ö10 & $\mathrm{f}$ \\
\hline \multirow{7}{*}{ 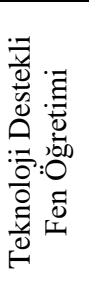 } & Öğrenme ortamını zenginleștirme & + & + & + & + & + & + & + & + & + & + & 10 \\
\hline & Etkili ve kalıcı öğrenme & + & + & + & + & + & + & + & + & + & - & 9 \\
\hline & Derse katılmada istekli olma & + & + & + & + & + & - & - & + & + & + & 8 \\
\hline & Araştırma becerilerini geliştirme & + & + & + & + & - & - & - & + & + & + & 7 \\
\hline & Öğrencinin motivasyonunu artırma & + & + & + & + & + & - & + & - & + & - & 7 \\
\hline & Öğrenme hızını artırma & - & - & + & + & - & - & + & + & + & + & 6 \\
\hline & Konuyu çok yönlü değerlendirme & + & + & - & - & - & + & - & + & & & 4 \\
\hline
\end{tabular}

Tablo 2 incelendiğinde Fen bilimleri öğretmenlerinin teknoloji destekli fen öğretimi hakkındaki görüşleri incelendiğinde öğretmenlerin büyük bir bölümü $(\mathrm{f}=10)$ fen öğretimi programının öğrenme ortamlarını zenginleştirdiğini ifade etmiştir. $\mathrm{Bu}$ görüşü etkili kalıcı öğrenme ( $\mathrm{f}=9)$ takip etmiştir. Öğretmenlerin cevaplarından bazıları aşağıda verilmiştir:

Fen Bilimleri dersinin bazı kazanımları soyut kavramlar içermektedir. Bu kavramların somutlaştırılmasında teknoloji destekli fen öğretimi oldukça avantajlıdır (Ö1).

Web 2.0 araçları, deneysel araçlar, gelişmiş laboratuvarlar, etkileşimli tahta gibi her türlü araç, gereç, yazılım, uygulama materyallerle fen öğretiminin desteklenmesidir. Bu şekilde öğrenme ortamları zenginleştirilir ve alternatif durumlar oluşturulur (Ö3).

Öğrencilerin zihninde konuların daha iyi şekillendiğini söyleyebilirim. Kavrama gücü bu sayede artiyor (Ö5).

Teknoloji destekli fen öğretimi öğrencilerde ilgiyi arttırmaktadır. Buna bağlı olarak ögrenciler derse katılımda istekli davranmaktadırlar (Ö9).

Fen Bilimleri öğretmenlerinin, fen öğretiminde kullanılan teknolojilere verdikleri örnekler Tablo 3'de verilmiştir.

Tablo 3. Fen bilimleri öğretmenlerinin, fen öğretiminde kullanılan teknolojilere verdikleri örnekler

\begin{tabular}{|c|c|c|c|c|c|c|c|c|c|c|c|c|}
\hline Tema & Kodlar & Ö1 & $\ddot{\mathrm{O}} 2$ & Ö3 & Ö4 & Ö5 & Ö6 & Ö7 & Ö8 & Ö9 & Ö10 & $\mathrm{f}$ \\
\hline \multirow{11}{*}{ 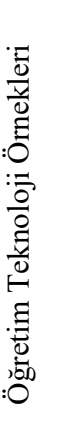 } & Eğitim Bilișim Ağ1 (EBA) & + & + & + & + & + & + & + & + & + & + & 10 \\
\hline & Simülasyonlar & + & + & + & + & + & + & + & + & + & + & 10 \\
\hline & Etkileşimli tahta & + & + & + & + & + & + & - & + & + & + & 9 \\
\hline & Bilgisayar ve tablet & + & + & + & + & - & + & + & + & - & + & 8 \\
\hline & Televizyon & + & + & + & + & + & - & - & + & + & - & 7 \\
\hline & Video ve animasyonlar & + & - & - & + & - & + & + & + & + & + & 7 \\
\hline & Sesli ve görüntülü materyaller & - & - & - & + & + & + & - & + & - & + & 5 \\
\hline & Üç boyutlu yazıcılar & - & + & + & - & + & - & - & - & + & + & 5 \\
\hline & Gerçek nesne ve modeller & + & + & + & + & - & - & - & + & - & - & 5 \\
\hline & Hologram & - & + & + & - & - & - & + & - & + & - & 4 \\
\hline & Captivate ve Articulate program 1 & - & - & + & - & + & & & + & & + & 4 \\
\hline
\end{tabular}


Tablo 3 incelendiğinde Fen bilimleri öğretmenlerinin öğretim teknolojilerine; Eğitim Bilişim A $\breve{g}(f=10)$, etkileşimli tahta $(f=9)$, bilgisayar ve tablet $(f=8)$, Televizyon $(f=7)$, video ve animasyonlar ( $\mathrm{f}=7$ ), Captivate ve Articulate programı $(\mathrm{f}=4)$ örnek verdikleri görülmektedir. Öğretmenlerin cevaplarından bazıları aşağıda verilmiştir:

Uzaktan eğitim başlamışılla en çok kullanılan öğretim teknolojileri Eğitim Bilişim Ağı başta olmak üzere, bilgisayar ve tableti örnek verebilirim (Ö1).

Soyut kavramların görselleştirilerek modellenmesi ya da ya benzetim yoluyla somutlaştırılması ve bu şekilde öğrenmeyi kolaylaştırılmasını sağlamaktadır. Örneğin simülasyon ya da animasyon kullanarak kavram yanılgısı riski azaltılır (Ö3).

Öğrenci seviyesine göre dikkat çekmek için animasyon ya da etkileşimli sunumlar hazırlamak ders başında kullanarak çocuğun konuya motivasyonunu sağlamaktır (Ö4).

Fen öğretiminde son dönemlerde etkileşimli sunumlar veya videolar hazırlamak için kullanılan Captivate ve Articulate programları kullanılmaktadır (Ö10).

Fen öğretiminde kullanılan teknolojilerin sınırlılıklarına ilişkin Fen Bilimleri öğretmenlerinin görüşleri Tablo 4'de verilmiştir.

Tablo 4. Fen öğretiminde kullanılan teknolojilerin sınırlılıklarına ilişkin fen bilimleri öğretmenlerinin görüşleri

\begin{tabular}{|c|c|c|c|c|c|c|c|c|c|c|c|c|}
\hline Tema & Kodlar & Ö1 & Ö2 & Ö3 & Ö4 & Ö5 & Ö6 & Ö7 & Ö8 & Ö9 & Ö10 & $\mathrm{f}$ \\
\hline \multirow{5}{*}{ 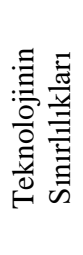 } & Yeterli alt yapının olmaması & + & + & + & + & + & + & + & + & + & + & 10 \\
\hline & Maliyetli olması & + & + & + & + & + & + & - & + & + & - & 8 \\
\hline & Zaman alıc1 olmas1 & + & + & - & + & - & + & + & + & + & + & 8 \\
\hline & $\begin{array}{l}\text { Ögrretmenlerin teknoloji yeterli } \\
\text { düzeyde kullanamaması }\end{array}$ & + & - & + & + & + & - & - & + & + & - & 7 \\
\hline & $\begin{array}{l}\text { Öğrencilerin yaratıcılığını } \\
\text { sınırlandırması }\end{array}$ & + & - & - & - & - & + & + & + & + & + & 5 \\
\hline
\end{tabular}

Tablo 4 incelendiğinde Fen Bilimleri öğretmenlerinin teknoloji destekli fen öğretiminde teknolojilerin sınırlılıklarını; yeterli alt yapının olmaması $(\mathrm{f}=10)$, maliyetli ve zaman alıcı olması $(\mathrm{f}=8)$, öğretmenlerin teknolojiyi yeterli düzeyde kullanamamaları $(\mathrm{f}=7)$ ve öğrencilerin yaratıcılığını sınırlandırması $(\mathrm{f}=5)$ şeklinde sıralamışlardır. Fen Bilimleri öğretmenlerinin cevaplarından bazıları aşağıda verilmiştir:

İster donanımsal araç olsun ister Web 2.0 uygulaması kapsamlı birçok teknoloji aracı ücretlidir. Örneğin EduLab çok güzel bir sanal laboratuvar ama çok yüksek ücret istiyor (Ö3).

Konuların yetişmesi zorlaşabiliyor. Vakit kaybı olabiliyor (Ö2).

Öğrenmeyi kolaylaştırsa da hazırcılığa alıştırarak yaratıcılığı sınırlıyor. Her ne kadar denemeler olsa da ölçme ve değerlendirmeye de entegre edilemiyor (Ö5).

Öğrenme aracın içeriği ile sınırlı kalıyor. Örneğin phet.colorado.edu yer alan bir atom simülasyonunda ya da ışı deneyleri simülasyonunda sadece o uygulamanın içeriği ile sınırlı oluyor. Kavrama ve uygulama basamağından sonra ilerleme zorlaşıyor (Ö9).

Alt yapı yetersizliği teknoloji destekli fen öğretimini uygulamada sınırlandırmaktadır (Ö6). verilmiştir.

Hologram teknolojisi konusunda Fen Bilimleri öğretmenlerinin görüşleri Tablo 5'de 
Tablo 5. Fen bilimleri öğretmenlerinin hologram teknoloji konusundaki görüşler

\begin{tabular}{|c|c|c|c|c|c|c|c|c|c|c|c|c|}
\hline Tema & Kodlar & Ö1 & Ö2 & Ö3 & Ö4 & Ö5 & Ö6 & Ö7 & Ö8 & Ö9 & Ö10 & $\frac{\mathrm{f}}{\mathrm{C}}$ \\
\hline \multirow{6}{*}{ 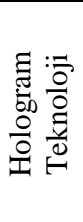 } & Derse olan ilgi ve dikkati artırma & + & + & + & - & - & + & + & + & + & + & 8 \\
\hline & Deneylerin gerçekmiş gibi uygulanmas1 & + & + & - & + & + & - & + & + & + & + & 8 \\
\hline & Üç boyutlu görüntü & - & + & + & + & - & + & + & + & - & + & 7 \\
\hline & Yüksek gerçeklik algısı & + & - & + & + & + & + & - & - & + & + & 7 \\
\hline & Yüksek çözünürlük & - & + & - & + & - & + & + & - & - & + & 5 \\
\hline & Derinlik algis1 & + & - & + & - & + & + & - & - & - & - & $\overline{4}$ \\
\hline
\end{tabular}

Fen Bilimleri öğretmenlerinin hologram teknolojisini; derse olan ilgi ve dikkati artırma $(\mathrm{f}=8)$, deneylerin gerçekmiş gibi uygulanması $(\mathrm{f}=8)$, üç boyutlu görüntü $(\mathrm{f}=7)$, yüksek gerçeklik algısı ( $\mathrm{f}=5)$ ve yüksek çözünürlük $(\mathrm{f}=5)$ kavramları açıklamışlardır.

Hologram teknolojisi ile yüksek çözünürlüklü görüntüler elde edilebilmektedir (Ö2).

Hologram teknolojisi düşünme yeteneği ve derinlik algısını olumlu yönde etkileyeceği de ifade edilmektedir (Ö5).

Hologram ışı̆̆ın kırılma ve yansıması özelliğinden yararlanarak herhangi bir nesne ya da iki boyutlu görüntünün 3B haline getirilmesidir (Ö7).

Yeni gelişen hologram teknolojisi Fen Bilimleri kazanımlarında yer alan canlılar konusu işlenirken öğrencilerin görmesi mümkün olmayan canlıları gerçekmiş gibi yansitarak görme imkânı sağlar (Ö8).

Hologram teknolojisinin öğrenme ortamında kullanılabilirliği hakkında Fen bilimleri öğretmenleri görüşleri Tablo 6'da verilmiştir.

Tablo 6. Hologram teknolojisinin öğrenme ortamında kullanabilirliğine ilişkin fen bilimleri öğretmenlerinin görüşleri

\begin{tabular}{|c|c|c|c|c|c|c|c|c|c|c|c|c|}
\hline Tema & Kodlar & Ö1 & Ö2 & Ö3 & Ö4 & Ö5 & Ö6 & Ö7 & Ö8 & Ö9 & Ö10 & $\mathrm{f}$ \\
\hline \multirow{6}{*}{ 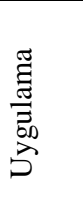 } & Maliyetli olmas1 & + & + & - & + & + & + & + & + & + & + & 9 \\
\hline & Alt yap1 yetersizliği & - & + & + & + & - & + & + & + & + & + & 8 \\
\hline & Öğretmenlerin bilgi eksikliği & + & + & + & - & - & + & - & + & + & - & 6 \\
\hline & Soyut konuları somutlaştırma & - & + & + & + & + & + & + & - & - & - & 6 \\
\hline & Kavram yanılgılarını giderme & - & - & + & - & - & + & + & + & + & - & 5 \\
\hline & Konuların etkili öğrenilmesi & + & + & + & - & - & - & - & - & - & + & 4 \\
\hline
\end{tabular}

Öğretmenler, maliyetli ( $\mathrm{f}=9$ ) ve alt yapının yetersiz olduğunu $(\mathrm{f}=8)$, hologram konusunda yeterli bilgiye sahip olmadıklarını $(\mathrm{f}=6)$ belirtmişlerdir. Buna karşın öğretmenler, soyut konuları somutlaştırdığını $(\mathrm{f}=6)$, kavram yanılgılarını giderdiğini $(\mathrm{f}=5)$ ve konuların etkili öğrenilmesini sağlayacağını ( $\mathrm{f}=4$ ) dile getirmişlerdir.

Örneğin Güneş sistemindeki gezegenleri hologram teknolojisi sayesinde öğrencilerin gözleri önüne serebiliyoruz. Zihinde soyut olarak kalan bilgiler bu sayede göz önüne gelerek kalıcı öğrenmeyi sağlıyor (Ö3).

Benzer bir çalışmayı robotlar üzerinde yapmıştık. Bunun dışında hologram ile görsel uzamsal birçok konu eğitimde rahatça verilebilir (Ö4).

Hologram teknolojisinin öğrenme ortamlarında kullanılması eğitim-öğretim için faydalı olacaktır. Üç boyutlu olarak verilen eğitimin ülkenin her yerine ulaştırılabilmesi her öğrencinin eşit bir eğitim almasına olanak sağlayacaktır. Tabi alt yapı sağlanmak şartıyla (Ö7).

$\mathrm{Bu}$ teknolojinin öğrenme ortamlarında kullanılabilmesi için gerekli eğitimlerin verilmesiyle ilgili problemler bulunmaktadır. Bu yüzden de sınıf ortamında kullanılması zorlaşmaktadır (Ö6).

Fen öğretiminde hologram teknolojisi kullanılmasının yararlarına yönelik öğretmenlerin görüşleri Tablo 7'de verilmiştir. 
Tablo 7. Fen bilimleri dersinde hologram teknolojisinin kullanılmasının yararlarına yönelik

\begin{tabular}{|c|c|c|c|c|c|c|c|c|c|c|c|c|}
\hline Tema & Kodlar & Ö1 & Ö2 & Ö3 & Ö4 & Ö5 & Ö6 & Ö7 & Ö8 & Ö9 & Ö10 & $\overline{\mathrm{f}}$ \\
\hline \multirow{6}{*}{ 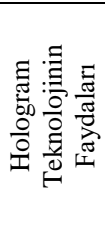 } & Konuların öğrenilmesini kolaylaştırma & + & + & + & + & - & + & + & + & + & + & 9 \\
\hline & Etkili bir sunum yapma & - & - & + & + & + & + & + & + & + & + & $\overline{8}$ \\
\hline & Öğrencilerin dikkatini çekme & - & + & + & + & + & + & - & - & + & + & 7 \\
\hline & Konuların somutlaştırılmasını sağlama & + & + & + & + & + & - & - & + & + & - & 7 \\
\hline & Konuların pekiştirilmesini sağlama & - & + & + & + & - & + & - & + & - & - & 5 \\
\hline & Akademik başarıyı artırma & - & - & - & - & - & + & + & + & + & - & 4 \\
\hline
\end{tabular}

Fen Bilimleri dersinde hologram teknolojisinin kullanılmasının faydalarını, konuların öğrenilmesini kolaylaştırma ( $\mathrm{f}=9$ ), etkili bir sunum yapma ( $\mathrm{f}=8)$, öğrencilerin dikkatini çekme $(f=7)$, konuların somutlaştırılmasını sağlama $(f=7)$, konuların pekiştirilmesini sağlama $(f=5)$ ve akademik başarıyı artırma $(\mathrm{f}=4)$ olarak öğretmenler dile getirmişlerdir. Öğretmenlerin cevaplarından bazıları aşağıda verilmiştir:

\begin{abstract}
Hologram teknolojisi ile birlikte özellikle fen derslerinde anlaşılması zor kavram ve uygulamaların daha kolay bir şekilde öğrenciye aktarılacağını düşünüyorum. Mesela moleküllerin ve bileşiklerin yapısı anlatılırken, soyut olan kavramları (özellikle molekül geometrisi vb.) hologramın sunduğu 3D teknolojisi sayesinde öğrenciye daha kolay ve somut bir şekilde sunulabilir (Ö2).

Hologram teknolojisi fen bilimleri kazanımlarında yer alan "Vücudumuzdaki Sistemler" konusunda organların üç boyutlu olarak gösterilmesi ve konunun bu şekilde öğrencilere aktarılmasıyla hem kalıcılığı arttırır hem de kavram yanılgılarını ortadan kaldırmış olur (Ö8).

Fen Bilimleri dersi öğretiminde hologram kullanılması dersi kolaylaştıracak bir teknolojidir. $\mathrm{Bu}$ sayede deneyler üç boyutlu olarak yapılabilirken, örneğin vücudumuzdaki sistemler ünitesinde öğrenci her detaya rahatça ulaşılabilecek öğrenme etkili ve kalıcı hale gelecektir (Ö10).
\end{abstract}

\title{
Sonuç, Tartışma ve Öneriler
}

Fen Bilimleri öğretmenlerinin fen öğretiminde kullanılan hologram uygulamalarına yönelik görüşlerinin belirlemesine yönelik yapılan bu araştırmadan elde edilen bulgular alanyazın 1şı̆̆ında yorumlanmıştır.

Teknoloji destekli fen öğretiminin, öğrenme ortamını zenginleştirdiğini, kalıc1 öğrenmeyi sağladığını, derse olan katılımı ve öğrenme hızını artırdığını, soyut kavramları somutlaştırma ve konuyu çok yönlü değerlendirme imkânı verdiğini öğretmenler belirtmişlerdir. Öğretmenlerin bu konuda görüş beyan etmelerinde, Web 2.0 ve deneysel araçların, gelişmiş laboratuvarların ve etkileşimli tahtaların öğrenme ortamlarında kullanılmasının faydalarını gözlemlemiş olmalarının etkili olduğu söylenebilir. $\mathrm{Bu}$ konuda yapılan çalışmalar incelendiğinde özellikle teknoloji destekli fen öğretiminin fen kavramlarını somutlaştırdığı ve kalıcı öğrenmeyi sağladığı tespit edilmiştir (Akdeniz, Öztürk ve Bakırc1, 2017; Yılmaz ve Sanalan, 2015). Çünkü teknolojik ürünler, öğrenme ortamını zenginleştirme ve alternatif öğrenme ortamı oluşturmaktadır. Benzer şekilde İnel, Evrekli ve Balım (2011)'ın yaptığ çalışmalarında öğretmen adaylarının, Fen ve Teknoloji dersinde teknolojiden faydalanılmasına iliş̧kin görüşlerinin belirlenmesini amaçlamışlardır. Araştırmanın sonuçlarına göre fen ve teknoloji öğretmen adaylarının derste eğitim teknolojilerinin kullanılmasına ilişkin olumlu görüşlere sahip oldukları tespit edilmiştir.

Fen Bilimleri öğretmenleri fen öğretiminde kullanılan teknolojilere; Eğitim Bilişim A $\breve{g}$ (EBA)'nı, simülasyonları, etkileşimli tahtayı, bilgisayarı, tabletleri ve televizyonu örnek olarak vermişlerdir. Bunun yanında Web 2.0 araçları, üç boyutlu yazıcılar ve hologramı örnek olarak ifade etmişlerdir. Öğretmenlerin bu örnekleri vermelerinde, fen öğrenme ortamında bu teknolojilerin sıklıkla kullanılmasının etkili olduğu düşünülmektedir. Bunun yanı sıra 
günümüzde Covid-19 salgını nedeniyle uzaktan eğitim yapılmaktadır. Bu eğitim yaklaşımında, öğretmenlerin bu teknolojilerde oldukça yararlanmış olmalarının etkili olduğu söylenebilir. Bu süreçte interaktif etkinlikler, animasyonlar, videolar bu süreçte dikkat çekmeyi daha da arttırmış ve öğretimin etkili şekilde gerçekleştirilmesine fayda sağlamıştır. Öğretim teknolojisinin doğru zamanda kullanılması ve öğrenci ile doğru ş̧ekilde buluşturulması fen öğretimine katk1 sağlayacaktır. Öğretim teknolojilerinin, öğretim programında yer alan kazanımlarla doğrusal olarak kullanılması konunun daha çekici ve verimli şekilde sunulmasını sağlamaktadır (Saklan ve Ünal, 2018). Öğretim teknolojileri kavramında ilk olarak bilgisayar ve internet dikkat çekse de, yazılı özgün kaynaklar, ilgili sesli ve görüntülü materyaller, gerçek nesne ve modeller, alana yazılmış eğitim programları da öğretim teknolojileri içerisinde yer alan örneklerdir (Aslan, 2015; Şahin ve Yıldırım, 1999).

Fen Bilimleri öğretmenleri fen öğretiminde kullanılan teknolojilerinin sınırlılıklarını şöyle açıklamışlardır. Bunlar; öğretmenlerin teknoloji kullanımında yetersiz oldukları, yeterli bilgiye sahip olmadıkları, maliyetli olması, zaman alıcı ve yeterli alt yapının olmaması şeklinde sıralanmıştır. Öğretmenler, öğrenme ortamında kullanılan teknolojilerin sinırlılıklarını ekonominin yeterli olmaması, okulların özel sektör tarafindan yeterince desteklenmemesi ve teknoloji ürünlerinin maliyetli olması ile açıklamışlardır. Diğer taraftan fen öğretiminde kullanılan teknolojilerin plansız şekilde kullanılmasının da öğrenme ortamında sınırlıkları ortaya çıkarmaktadır. Çünkü sınırlı zamanda kullanılan plansız eğitim teknolojisi, öğrenme ortamında istenilen etkili öğretimi sağlamayabilir. Bilgisayar destekli öğretim uygulamalarının ortaokul öğrencilerinin bilimsel düşünme becerileri üzerine etkisinin araştırıldığ öğretiminde kullanılan teknolojilerin sınırlılıklarında maliyetli olması ve yeterli alt yapının olmamasına dikkat çekilmiştir (Öztürk, Akdeniz ve Bakırcı, 2017). Başka bir çalışmada, teknoloji destekli öğretimin fen bilgisi öğretmen adaylarının üzerinde olumlu etkiler oluştururken, diğer taraftan teknoloji destekli fen öğretiminin sınırlılıklarının bu olumlu etkiye gölge düşürdüğü saptanmıştır. Aynı zamanda fen bilimlerinin teknolojiyle olumlu bir entegrasyonunun olabileceği ve fen bilimlerine dair yenilikçi yaklaşımların da kazandırılabileceği öngörülmektedir (Hançer, Şensoy ve Yıldırım, 2003). Bu konuda yapılan çalışmaların, bu çalışmanın sonuçları ile büyük oranda örtüştüğü görülmüştür.

Fen Bilimleri öğretmenlerinin hologram teknolojisi konusundaki görüşleri alınmıştır. Çalışmaya katılan öğretmenlerin yaklaşık üçte birinin fen öğretiminde kullanılan hologram teknolojisini yeterli düzeyde kullanamadıkları ve konuda sıkıntılar yaşadıkları görülmüştür. Öğretmenler hologram teknolojine fen öğretimde kullanmamalarını teknoloji okuryazarlıklarının yeterli düzeyde olmamasıyla açıklamışlardır. $\mathrm{Bu}$ sıkıntılara rağmen öğretmenler, hologram teknolojisinin öğrenme ortamındaki olumlu yönlerini ifade etmişlerdir. $\mathrm{Bu}$ olumlu özellikler, öğrencilerin ilgi ve dikkatlerini artırma, üç boyutlu görüntü sağlaması, yüksek gerçeklik algısı ve deneyleri laboratuvarda yapılıyor gibi hissettirmeleri şeklinde sıralanmıştır. Teknolojinin gelişme adına hızlı bir ivme kazanmasıyla teknolojiye olan ilgi artmış ve bu gelişme eğitim alanına da yansımıştır. Son zamanlarda eğitim dünyasında dijital teknolojiler öğrenme aracı olarak kullanılmaya başlanmıştır. 21.yüzyılda dijital teknolojiler denilince akla gelenlerden biri de sanal gerçeklik ve hologramdır (Katsioloudis ve Jones, 2018). Öne çıkan özellikleri ele alındığında; sanal objeler ile gerçekçi ortam ve işler sunmak, sanal ortamı gerçek zeminde sunarak öğrenmeyi kolay, sürekli ulaşılabilir hale getirmek gibi özellikler karşımıza çıkmaktadır. Y ve $Z$ kuşakları düşünüldügünde onlar için cazip ve etkili ortamlar oluşturmak, eğitim ve uygulamalarda bu teknolojileri önemli ve öncelikli hale getirmektedir (Huang, Chen ve Chou, 2016).

Hologram teknolojisinin öğrenme ortamlarında kullanılabilirliği ile ilgili Fen Bilimleri öğretmenleri farklı görüşler beyan etmişlerdir. Öğretmenler, hologram teknolojisi konusunda hem olumlu hem de olumsuz görüşlerinin olduğu belirlenmiştir. Katılımcılar fen öğretiminde hologram teknolojinin sinırlılıklarını, öğretmenlerin hologram teknoloji konusunda yeterli bilgi ve beceriye sahip olmadıkları, alt yapının yetersiz ve maliyetli olduğunu dile getirmişlerdir. 
Öğretmenlerin hologram teknolojisini öğrenme ortamında kullanmamaları ve üniversite öğrenim döneminde öğretim teknolojileri ile ilgili yeterli ders almamış olmaları etkili olmuş olabilir. Öğretmenlerin hologram teknolojisi ile ilgili alt yapının yetersiz olma görüşlerinde, bu teknolojinin maliyetli olması, öğretmenlerin derste kullanım konusunda isteksiz olmaları ve yöneticilerin bu konuda yeterli düzeyde bu teknolojinin faydalarını bilmemelerinin etkili olduğuna inanılmaktadır. Öğretmenler fen öğretiminde kullanılan hologram teknolojisinin olumlu yönlerini, soyut konuları somutlaştırma, konunun anlaşılırlığını sağlama ve gerçekçi ortam oluşturma gibi olumlu özelliklerini ifade etmişlerdir. Bu konu ile ilgili literatür taramasında sınırlı sayıda çalışmaya ulaşılmış, incelenen çalışmalarda da genel olarak yeni nesil ders malzemelerinin sanal gerçek ve artırılmış gerçeklik etkileşimli ürünlerden oluştuğu vurgulanmıştır (Bilgin, 2019; Yılmaz ve Sanalan, 2015). Bu yönüyle sanal gerçeklik, tüm eğitim aşamaları için çok uygun ürün ve donanımlar sunmaktadır. Müfredatta yer alan olgu, mekân, yöntem ve nesneler üç boyutlu olarak öğrencilere gerçekçi bir algıyla sunulmaktadır. Bu duruma Coğrafya veya Tarih derslerinde, bir olay anlatılırken öğrencilerin mekânı, ortamı ve olayı görüp yaşayarak eğitim alması örnek verilebilir. Bu da öğrenmeyi cazip ve kalıcı hale getirerek öğrencilerin kolay kolay yaşayamayacağ (Akpınar ve Ergin, 2005).

Fen Bilimleri öğretmenleri, Fen Bilimleri dersinde hologram teknolojisinin birçok yararlarının olduğunu belirtmişlerdir. $\mathrm{Bu}$ yararların, konuların öğrenilmesini kolaylaştırma, öğrencilerin konuya dikkatlerini çekme, akademik başarıyı artırma, konuları somutlaştırma ve pekiştirme olduğu görülmüştür. Öğretmenlerin hologram teknolojisinin yararlarını ifade etmelerinde, hologram teknolojinin derinlik algısının olmasının ve öğrencilere bir nesneyi üç boyutlu olarak inceleme imkânı vermesinin etkili olduğu düşünülmektedir. Öğretmenlerin, Fen Bilimleri dersinde hologram teknolojinin yararlarına örnekler verdikleri görülmüştür. Öğretmenler Fen Bilimleri dersinde bir hayvanın anatomisini, iç organlarını, kanın damarlarda nasıl dolaştı̆̆ını ve kalbin nasıl attığını hologram teknolojisi ile öğrencilere gösterdiklerini örnek vermişlerdir. Bu durum, konunun somutlaştırmasını, öğrencilerin canlı olarak insan vücudunda meydana gelen olayları doğrudan gözlem yapmasını ve dikkatlerini çekmesini sağlamaktadır. Bu şekilde hologram destekli fen öğretimi, öğrenciler için eğlenceli hale geldiği için etkili öğrenme gerçekleştiği söylenebilir. Yapılan bir çalışmada, hologram destekli fen öğretimi ile konuların, sanal ve artırılmış gerçeklik ile desteklenmiş fen öğretiminden daha etkili olduğu saptanmıştır (Türk, 2020). Araştırmadan elde edilen bulgulara göre aşağıda yer alan önerilerde bulunulmuştur:

Günümüzde eğitimde sıklıkla kullanılan simülasyon, akıllı tahta vb. teknolojiler yerine yenilikçi teknolojiler arasında yer alan dijital hologramın sınıf ortamında kullanılabileceği ve öğrencilerin bu teknoloji sayesinde daha verimli bir öğretim ortamında fen kazanımlarını öğrenileceği düşünülmektedir.

Yenilikçi teknolojiler arasında yer alan dijital hologramın sınıf ortamına taşınabilmesi için öğretmenlerin bu teknolojilerden haberdar olması ve bu konu hakkında çalışmalara katılmaları gerektiği düşünülmektedir.

Fen Bilimleri derslerindeki soyut kavramların somutlaştırılmasında ya da günlük hayatta öğrencilerin gözlem imkânı bulamayacağı güneş sistemi gibi konularda onlara gerçeklik hissini yaşatacak olan dijital hologramlardan yararlanılabileceği düşünülmektedir.

\section{Kaynakça}

Akdeniz, A. R. ve Öztürk, M. ve Bakırcı H. (2017). Bilgisayar destekli öğretim uygulamalarının sekizinci sınıf öğrencilerinin fen dersi akademik başarılarına ve bilginin kalıcılığına etkisi. Hasan Ali Yücel Eğitim Fakültesi Dergisi, 14(2), 59-77. 
Akpınar, E. ve Ergin, Ö. (2005). Yapılandırmacı kuramda fen öğretmeninin rolü. İlköğretim Online Dergisi, 4(2), 55-64.

Alkan, C. (2005). Eğitim teknolojisi. (7. Baskı). Ankara: Anı Yayıncılık.

Artun, H., Durukan, A. ve Temur, A. (2020). Effects of virtualy reality enriched science laboratory activities on pre-service science teachers' science process skills. Education and Information Technologies, 25, 5477-5498.

Aslan, B. (2015). Öğretim teknolojileri ve materyal tasarımı dersinin İngilizce ögrretmenlerinin mesleki kazanımlarına etkisi: Muğla İli Örneği (Yayımlanmamış yüksek lisans tezi). Muğla Sitkı Koçman Üniversitesi, Muğla.

Aslan, R. (2017). Uluslararası rekabette yeni imkânlar: Sanal gerçeklik, artırılmış gerçeklik ve hologram. Ayrintı Dergisi, 5(49).

Aslan, R. ve Erdoğan, S. (2017). 21. yüzyılda hekimlik eğitimi: Sanal gerçeklik, artırılmış gerçeklik, hologram. Kocatepe Veterinary Journal, 10(3), 204-212.

Baker, E. J., Bakar, J. A. A., \& Zulkifli, A. N. (2017). Mobile augmented reality elements for museum hearing impaired visitors' engagement. Journal of Telecommunication, Electronic and Computer Engineering, 9(2-12), 171-178.

Bilgin, H. (2019). Fen bilimleri öğretmenlerinin fen bilimleri dersi için geliştirilmiş bir android tabanlı mobil uygulamaya yönelik görüşlerinin incelenmesi (Yayımlanmamış yüksek lisans tezi). Niğde Ömer Halisdemir Üniversitesi, Niğde.

Bozkuş, E. (2002). İlköğretim ikinci aşamasında matematik öğretiminde bilgisayar kullanmanın ögrenci başarısı üzerine yansıması (Yayımlanmamış yüksek lisans tezi). Yüzüncü Yı1 Üniversitesi Fen Bilimleri Enstitüsü, Van.

Büyüköztürk, Ş., Kılıç-Çakmak, E., Akgün, Ö.E., Karadeniz, Ş. ve Demirel, F. (2008). Bilimsel araştırma yöntemleri (14. Baskı). Ankara: Pegem Yayınları.

Chen, C. P., \& Wang, C. H. (2015). Employing augmented reality embedded instruction to disperse the imparities of individual differences in earth science learning. Journal of Science Education and Technology, 24(6), 835-847.

Çepni, S. (2014). Araştırma ve proje çalışmalarına giriş. Trabzon: Celepler Matbaacılık.

Durukan, A., Artun, H., \& Temur, A. (2020). Virtual reality in science education: A descriptive review. Journal of Science Learning, 3, 132-142.

Ekiz, D. (2009). Bilimsel araştırma yöntemleri: Yaklaşım, yöntem ve teknikler. Anı Yayıncılık.

Ghuloum, H. (2010 ). 3D Hologram technology in learning environment. In E. Cohen (Ed.), Proceeding of information science \& IT education conference (pp. 693-704). Italy: Information Science Institute.

Hackett, M., \& Proctor, M. (2016). Three dimensional display technologies for anatomical education a literature review. Journal of Science Education and Technology, 25(4), 641-654.

Hançer, A. H., Şensoy, Ö. ve Yıldırım, H. İ. (2003). İlköğretimde çağdaş fen bilgisi öğretiminin önemi ve nasıl olması gerektiği üzerine bir değerlendirme. Pamukkale Üniversitesi Eğitim Fakültesi Dergisi, 13(13), 80-88.

Huang, T. C., Chen, C. C., \& Chou, Y. W. (2016). Animating eco education to see feel and discover in an augmented reality based experiential learning environment. Computers \& Education, 96, 72-82.

İnel, D., Evrekli, E. ve Balım, A. G. (2011). Öğretmen adaylarının fen ve teknoloji dersinde eğitim teknolojilerinin kullanılmasına ilişkin görüşleri. Kuramsal Eğitimbilim, 4(2), 128-150. 
Kara, Y. (2018). Determining the effects of microscope simulation on achievement, ability, reports, and opinions about microscope in general biology laboratory course. Universal Journal of Educational Research, 6, 1981-1990.

Kara, Y., \& Bakırc1, H. (2018). A scale to assess science activity videos (SASAV): The study of validity and reliability. Journal of Education and Training Studies, 6(1), 43-51.

Karademir, E., Sarikahya, E. ve Altunsoy, K. (2017). Fen bilimleri öğretmenlerinin beceri kavramına yönelik algıları: Bir olgubilim çalışması. Eskişehir Osmangazi Üniversitesi Sosyal Bilimler Dergisi, 18(1), 53-71.

Katsioloudis, P. J., \& Jones, M. V. (2018). A comparative analysis of holographic, 3D printed, and computer generated models: implications for engineering technology students' spatial visualization ability. Journal of Technology Education, 29(2), 36-53.

Khurmyet, G. (2016). Mobil eğitim teknolojisi olarak tablet bilgisayarların etkin ögrenim amaçlı kullanımı: özel ortaögretim kurumları üzerine bir araştırma (Yayımlanmamış yüksek lisans tezi). Marmara Üniversitesi, İstanbul.

Miles, B. M., \& Huberman A. M. (1994). Qualitative data analysis: An expanded source book. California, USA: Sage Publications.

Mnaathr, S. H., \& Basha, A. D. (2013). Descriptive study of 3D imagination to teach children in primary schools: Planets in outer space (Sun, Moon, Our Planet). Computer Science and Information Technology, 1(2), 111-114.

Okulu, H. Z. ve Ünver, A. O. (2016). Bring cosmos into the classroom: 3D hologram. Shelley, M., Kıray, A., \& Çelik, İ. (Ed), Education Research Highlights in Mathematics, Science and Technology (s. 81-86).

Olson, D. W. (2013). Simple, complete, and novel quantitative model of holography for students of science and science education. Journal of Physics: Conference Series, 415(1), 17.

Orcos, L., \& Magrenan, A. A. (2018). The hologram as a teaching medium for the acquisition of STEM contents. International Journal of Learning Technology, 13(2), 163-177.

Öztürk, M., Akdeniz, A. R. ve Bakırcı, H. (2017). Bilgisayar destekli öğretim uygulamalarının ortaokul öğrencilerinin bilimsel düşünme becerileri üzerine etkisi. Yüzüncü Yll Üniversitesi Ĕgitim Fakültesi Dergisi, 14(1), 611-639.

Patton, M. Q. (2002). Two decades of developments in qualitative inquiry: A personal, experiential perspective. Qualitative Social Work, 1(3), 261-283.

Roslan, R. K., \& Ahmad, A. (2017). 3D spatial visualisation skills training application for school students using hologram pyramid. International Journal on Informatics Visualization, 1(4), 170-174.

Saklan, H. ve Ünal, C. (2018). Teknoloji dostu fen bilimleri öğretmenlerinin eğitim bilişim ağı hakkındaki görüşleri. Necatibey Eğitim Fakültesi Elektronik Fen ve Matematik Eğitimi Dergisi, 12(1), 493-526.

Sipahioğlu, S. (2019). Fen bilimleri öğretmenlerinin eğitimde teknoloji kullanımına yönelik tutumlarının çeşitti değişkenlere göre incelenmesi (Yayımlanmamış yüksek lisans tezi). Atatürk Üniversitesi, Erzurum.

Sotiriou, S., \& Bogner, F. X. (2008). Visualizing the invisible: Augmented reality as an innovative science education scheme. Advanced Science Letters, 1(1), 114-122. 
Şahin, O. N. ve Uyar, S. (2019, Nisan). Muhasebe eğitiminde yeni teknolojiler: Hologram tekniği. 40 Yılın Muhasebesi ve Yeni Hayallerimiz Sempozyumu, Denizli.

Şahin, T. Y. ve Yıldırım, S. (1999). Öğretim teknolojileri ve materyal geliştirme. Ankara: Anı Yayıncilik.

Turan Güntepe, E. (2020). Etkileşimli hologram teknolojisiyle okul öncesi kavramlarının ögretimi (Yayımlanmamış doktora tezi). Trabzon Üniversitesi, Trabzon.

Tüfekçi-Hotomaroğlu, A. (1997). Bilgisayar destekli öğretimde ders yazllımlarının değerlendirilmesi. (Yayımlanmamış yükssek lisans tezi). Gazi Üniversitesi, Ankara.

Türk. H. (2020). Fen eğitiminde yenilikçi teknoloji uygulamalart: Dijital hologram örneği (Yayımlanmamış yüksek lisans tezi). Eskişehir Osmangazi Üniversitesi, Eskişehir.

Walker, R. A. (2013). Holograms as teaching agents. Journal of Physics: Conference Series, $415(1), 1-5$.

Yamaguchi, T., \& Yoshikawa, H. (2012). New education system for construction of optical holography setup tangible learning with augmented reality. Journal of Physics, 415(1), 1-8.

Yıldırım, A. ve Şimşek, H. (2011). Sosyal bilimlerde nitel araştırma yöntemleri. Ankara: Seçkin Yayıncilik.

Yılmaz, Ö. ve Sanalan, V. A. (2015). Fen öğretiminde katılımlı ve motive edici sınıf ortamı mobil teknoloji kullanımı. On Dokuz Mayıs Üniversitesi Eğitim Fakültesi Dergisi, 34(2), 3750 .

\section{ETİK ve BİLIMSEL İLKELER SORUMLULUK BEYANI}

$\mathrm{Bu}$ çalı̧̧manın tüm hazırlanma süreçlerinde etik kurallara ve bilimsel atıf gösterme ilkelerine riayet edildiğini yazar(lar) beyan eder. Aksi bir durumun tespiti halinde Afyon Kocatepe Üniversitesi Sosyal Bilimler Dergisi'nin hiçbir sorumluluğu olmayıp, tüm sorumluluk makale yazarlarına aittir. Yazarlar etik kurul izni gerektiren çalışmalarda, izinle ilgili bilgileri (kurul adı, tarih ve sayı no) yöntem bölümünde ve ayrıca burada belirtmişlerdir.

Kurul adı: Yüzüncü Y1l Üniversitesi Rektörlüğü Sosyal ve Beşeri Bilimleri Etik Kurulu

Tarih: 17/02/2021

No: 2021/02-14

\section{ARAŞTIRMACILARIN MAKALEYE KATKI ORANI BEYANI}

1. yazar katkı oranı : \% 50

2. yazar katkı oranı : \% 30

3. yazar katk1 oran $1 \% 20$ 